\title{
Serological evidence of continued Japanese encephalitis virus transmission in Singapore nearly three decades after end of pig farming
}

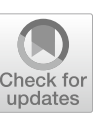

\author{
Grace Yap ${ }^{1,2}$, Xiao Fang Lim', Sharon Chan ${ }^{3}$, Choon Beng How³ ${ }^{3}$ Mahathir Humaidi ${ }^{*} \mathbb{D}$, Gladys Yeo ${ }^{1}$, \\ Diyar Mailepessov ${ }^{1}$, Marcella Kong ${ }^{1}$, Yee Ling Lai ${ }^{1}$, Chiharu Okumura ${ }^{4}$ and Lee Ching Ng${ }^{1}$
}

\begin{abstract}
Background: Singapore used to report an annual average of 14 cases of Japanese encephalitis, but ever since the abolishment of pig farms in the early 1990s, the local incidence rate for Japanese encephalitis virus (JEV) infections has reduced drastically. Studies done in the early 2000s demonstrated the presence of JEV-specific antibodies in animals such as wild boars, dogs, chickens and goats on the offshore island and peripheral parts of the Singapore, indicative of prior JEV exposure. A JEV wildlife and sentinel chicken surveillance system was initiated in 2010 through to 2017 to study the animal host seroprofiles.
\end{abstract}

Results: A total of 12/371 (3.23\%) of resident bird samples, 24/254 (9.45\%) of migratory bird samples and 10/66 (15.16\%) of wild boar samples were positive for the presence of JEV antibodies. Seroconversions in sentinel chickens were observed at two time points. Through this study, two sites with active transmission of JEV amongst avian or porcine hosts were identified.

Conclusions: JEV transmission in animal hosts has continued despite the phasing out of pig farming nearly thirty years ago; however, the public health risk of transmission remains low. Environmental management for mosquito population remains key to keeping this risk low.

Keywords: Japanese encephalitis virus (JEV), Singapore, Wild pigs, Migratory birds, Wild birds

\section{Background}

Japanese encephalitis is endemic in many Asian countries and contributes to a large disease burden, with approximately 30,000 to 50,000 reported cases, and 10,000 deaths annually [1]. Epidemics of encephalitis have been described since the 1870s in Japan, with the first isolation of the Japanese encephalitis prototype Nakayama strain in 1935 from the brain of a fatal human case. Japanese encephalitis virus (JEV) has subsequently been isolated in China and the Asian subcontinent, all of South East Asia and the Pacific Rim, and reached the northern regions of Australia in 1998 [2, 3]. JEV is divided into five genotypes (GI to GV) with GIII as the source of numerous

\footnotetext{
*Correspondence: Mahathir_Humaidi@nea.gov.sg

1 Environmental Health Institute, National Environment Agency,

Singapore, Singapore

Full list of author information is available at the end of the article
}

epidemics throughout history. However, there have been reports of replacement of GIII with GI in the recent years $[4,5]$. This genotype replacement was hypothesized to be linked to viral genetic determinants related to selective advantages in the mosquito vectors.

Singapore used to report an annual average of 14 cases of JEV until the abolishment of pig farms in 1992 [6-11]. JEV transmission involves pigs as the amplifying host and ardeid birds as the reservoir host, with Culex tritaeniorhynchus as the primary vector, and humans as the accidental dead-end host [12]. After 1992, the local incidence of JEV infections reduced drastically. From 1991 to 2000 there were three imported cases of JEV. In 2001, two local cases were reported and the latest case, in May 2005, reported a 53-year-old man, whose serum sample tested positive for JEV [13]. JEV-specific antibodies were also detected in animals such as wild boars, dogs, chickens 
and goats in 2002 and 2004 on the offshore islands and rural parts of Singapore [14, 15]. These antibody profiles served as an important indicator that JEV transmission could be active in those areas among the avian and porcine hosts. In countries where JEV transmission is apparent, animals similarly display the presence of neutralizing antibodies in their blood [16, 17]. The Eurasian wild pigs (Sus scrofa Linnaeus), which were once thought to be extinct in Singapore have re-colonized areas such as the Central Catchment Nature Reserve (CCNR) and the western catchment areas in the past decade. It is estimated that over 500 wild pigs inhabit the CCNR. Small population clusters are also found on the eastern side of Singapore [18]. The expansion of the appropriate amplifying host population may contribute to the continued risk of JEV transmission in Singapore.

A plausible source of JEV is migratory birds which can serve as viral reservoirs. Over 90 bird species have been identified as amplifying and reservoir hosts of JEV. Among them, egrets (Egretta garzetta) and herons (Nycticorax nycticorax) from the family Ardeidae are particularly susceptible to JEV infection, and are known to develop high viral titers $[19,20]$. During each migratory season from September to March, birds fly along the East-Asia Australasian Flyway (EAAF) and stopover at a Singapore's Nature Reserve (NR). These birds fly from as far north as the Arctic Circle, across East and South East Asia, and journey southwards to Australia and New Zealand. Migratory birds are thought to be one of the factors involved in the introduction of JEV GI from South East Asia in the early 1990s to more temperate regions such as northern Vietnam and eastern Asia (Japan and Korea) $[3,21]$.

This study aims to give an updated seropositivity profile of JEV among animals in Singapore, particularly in local and migratory birds, and in wild boar samples collected from 2011 to 2017.

\section{Methods}

\section{Collection of migratory/resident bird sera and dead bird carcases}

Nature Reserve (NR) houses a variety of resident birds, and is also visited by both long- and short-distance migratory birds. NR has an existing bird ringing programme to collect bio-data from the migratory birds that visit this pit-stop. Tagging onto this programme that has been on-going since 1990, 254 blood samples were taken from the migratory birds that were caught during the migratory session (every September to March) from 2010 to 2017. Jugular vein blood samples of not more than $1 \%$ body weight of birds were drawn aseptically into EDTA tubes by avian veterinarians. After sampling, an equivalent volume of $10 \%$ glucose was injected for replenishment. Blood samples were transferred on ice to the Environmental Health Institute, a public health laboratory under the National Environment Agency of Singapore. The plasma was separated by centrifugation at $4000 \mathrm{rpm}$ for $4 \mathrm{~min}$ and kept at $-80{ }^{\circ} \mathrm{C}$ until further processing.

Through a donor bird programme at the Avian Sanctuary (AS) where the public can submit injured birds found elsewhere in the country, 372 bird serum samples were obtained during the same period. The collection also included 1024 dead bird carcasses. These carcasses were dissected, and their organs (heart, liver, spleen, lungs, kidneys and brain) were stored at $-80^{\circ} \mathrm{C}$ for bio-banking purposes.

\section{Collection of wild boar sera}

Sixty-six wild boar blood samples were collected as part of wild boar population management programme in Central Catchment Nature Reserve (CCNR) in 2014, where wild boar activity was previously documented. Animals' physical characteristics such as size and weight were recorded. Blood was kept and transferred to the laboratory on ice. The plasma was separated by centrifugation at $4000 \mathrm{rpm}$ for $4 \mathrm{~min}$ and kept at $-80^{\circ} \mathrm{C}$ until further processing.

\section{RNA extraction and real-time RT-PCR}

A total of 1024 bird brain samples were each homogenized in $500 \mu \mathrm{l}$ of virus transport media (Copan Diagnostics, California, USA) using a Mixer Mill MM 400 (Retsch Technology GmbH, Haan, Germany). A volume of 140 $\mu \mathrm{l}$ of viral RNA was extracted from each brain specimen and blood sample by using a QIAamp viral RNA mini kit (Qiagen, Hilden, Germany) according to the manufacturer's instructions.

A duplex JEV and West Nile (WN) real-time reverse transcription polymerase chain reaction (RT-PCR) protocol was optimised based on protocols by Scherret et al. [22] and Santhosh et al. [22, 23]. A pan-flavivirus RT-PCR adopted from Yang et al. [26] was also performed. Extracted RNA was subjected to both PCR reactions. Primers from Yang et al. [26], Scherret et al. [22] and Santhosh et al. [23] were utilized. Briefly, the reaction occurred in a final volume of $20 \mu \mathrm{l}$, comprising $5 \mu \mathrm{l}$ of RNA template and a concentration of $10 \mu \mathrm{M}$ for each primer in a Lightcycler ${ }^{\circledR} 2.0$ (Roche Diagnostics GmbH, Mannheim, Germany). The cycling conditions were as follows: reverse transcription at $50{ }^{\circ} \mathrm{C}$ for $20 \mathrm{~min}$, inactivation at $95{ }^{\circ} \mathrm{C}$ for $15 \mathrm{~min}$ and subsequently 40 cycles of $94{ }^{\circ} \mathrm{C}$ for $15 \mathrm{~s}, 55{ }^{\circ} \mathrm{C}$ (JE-WN) or $58{ }^{\circ} \mathrm{C}$ (Flaviviruses) for $30 \mathrm{~s}$ and $72{ }^{\circ} \mathrm{C}$ for $30 \mathrm{~s}$. Melting curve analysis was conducted at $65{ }^{\circ} \mathrm{C}$ for $15 \mathrm{~s}$ continued with a cooling step at $37{ }^{\circ} \mathrm{C}$ for $20 \mathrm{~s}$ for amplified products accuracy verification. 


\section{Sentinel chicken for passive surveillance in NR}

From 2013 to 2018, a sentinel chicken surveillance was established at NR. As part of this surveillance, three to five sentinel chickens (Gallus domesticus) were deployed at NR for monitoring of specific zoonotic diseases, particularly arboviruses (arthropod-borne viruses). As mosquito-borne viruses such as JEV utilize birds in their transmission cycles, chickens are good sentinels and can act as an early warning system [24, 25]. Monthly blood samples were collected and processed. All procedures were approved and carried out in accordance to the Environmental Health Institute's Institutional Animal Care and Committee (IACUC) guidelines (IACUC005). The plasma samples were subsequently subjected to immunofluorescence assay (IFA) to determine for the presence of seroconversion for JEV.

\section{Detection of JEV antibodies in resident/donor birds, wild boars and sentinel chickens using immunofluorescence assay (IFA)}

The plasma samples separated from mammal and bird blood were subjected to IFA assay to determine the seropositivity. JEV (Nakayama strain, courtesy of Dr Y. C. Chan) was cultured in Vero cells (ATCC CCL-81) in the biosafety level 3 (BSL3) laboratory at the Environmental Health Institute. Immunofluorescence slides were made, inactivated and transferred out of the BSL3 to BSL2 where the IFA was performed. Animal plasma was diluted 1:50 in 5\% skim milk (Oxoid, Kansas, USA) and applied onto the JEV IFA slides. Incubation was performed in a humidifier at $37{ }^{\circ} \mathrm{C}$ for $30 \mathrm{~min}$ before washing with $1 \times$ PBS. Secondary antibody anti-bird IgFITC (Bethyl Laboratories, Texas, USA) or anti-pig IgFITC (Bethyl Laboratories) was applied onto the slides, depending on the animal sera tested. Incubation and washing were repeated before visualization of fluorescence was performed.

\section{Plaque reduction neutralization assay}

Samples that were positive in the IFA were subjected to plaque reduction neutralization assay (PRNT). PRNT, adapted from Nemeth et al. [26-28], was carried out in 24-well plates seeded with baby hamster kidney cells (BHK21, ATCC CCL-10) at 90\% confluence. The animal plasma samples were heat inactivated at $56{ }^{\circ} \mathrm{C}$ for $30 \mathrm{~min}$ before use. Samples were serially diluted from 1:5 to $1: 500$, and $100 \mu \mathrm{l}$ of each dilution was incubated with $100 \mu \mathrm{l}$ of JEV virus (20 pfu/well) (making the final dilution of the sera 1:10, 1:100 and 1:1000, respectively) at $37{ }^{\circ} \mathrm{C}$ for $1 \mathrm{~h}$. The antibody and virus mixtures were then added to the wells of the 24-well plates containing the BHK cells. The medium was aspirated after $1 \mathrm{~h}$ of incubation at $37^{\circ} \mathrm{C}$. BHK cells were overlaid with 1 $\mathrm{ml}$ of $1 \%$ carboxymethylcellulose in RPMI medium supplemented with $2 \%$ FCS. The plates were incubated at $37{ }^{\circ} \mathrm{C}$ for approximately $5-6$ days with $5 \% \mathrm{CO}_{2}$. Subsequently, each well was fixed with formaldehyde (20\%) for $30 \mathrm{~min}$ and stained with napthol blue black stain solution. $\mathrm{PRNT}_{80}$ was used to differentiate any crossneutralizating antibodies from the same JEV serocomplex. The $\mathrm{PRNT}_{80}$ titre was calculated by counting plaques and reporting the titre as the reciprocal of the last serum dilution to show $80 \%$ reduction of control plaques ( $\leq 4$ plaques) based on approximately $20 \mathrm{pfu}$ of virus added to each sample.

\section{Results}

A total of 371 donor bird sera were screened for JEV antibodies by IFA, followed by the confirmation of neutralizing antibodies by PRNT. The panel of birds included species such as buzzards, bitterns, eagles, egrets, flamingos, hawks, herons, hornbills, kingfishers, koels, owls, pigeons, pittas and turacos. Twelve out of 371 (3.23\%) registered JEV neutralizing antibodies, with an end point titre ranging from $10^{1}-10^{3}$ (Table 1 ).

Besides ardeid birds (black-crowned night heron, cattle egret and little egret), which are the typical avian reservoirs of JEV, raptors (crested goshawk, honey buzzard and white-bellied sea eagle) also showed JEV neutralizing antibodies. The common birds in this collection (crows, mynahs, pigeons, doves, herons, egrets and bitterns) are considered as part of the native bird community.

A total of 254 plasma samples were collected from migratory birds which included plovers (golden Pacific plovers, Charadrius mongolus; Mongolian plovers, Pluvialis fulva) and common redshanks (Tringa tetanus). Out of this, 24 (9.45\%) samples collected from 2010 to 2012 registered neutralizing antibodies towards JEV (Table 2).

Of 66 wild boar samples screened, 10 (15.16\%) plasma samples had JEV neutralizing antibodies, with an end point titre ranging from $10^{1}-10^{3}$ (Table 1 ).

Three to five sentinel chickens were placed in NR since 2013 for passive surveillance of specific zoonotic diseases. Seroconversion was observed in October 2013 and November 2014, with an end point titre ranging from $10^{1}$ to $10^{2}$ (Table 1 ). There was no seroconversion from then until the sentinel chicken surveillance was ceased in August 2018.

None of the sera or tissues was positive for JEV RNA by real-time RT-PCR. 
Table 1 JEV seropositivity among donor birds, wild boars and sentinel chickens. Seropositivity was confirmed by PRNT after IFA screening. PRNT 80 end point titre was determined by counting plaques and reporting the titre as the reciprocal of the last serum dilution to show $80 \%$ reduction of control plaques ( $\leq 20$ plaques) counted based on the 100 pfu of virus added to each sera sample

\begin{tabular}{|c|c|c|c|c|c|}
\hline Sample ID & Bird species & Sex/Age group & Location & Date collected & $\begin{array}{l}\text { PRNT }_{80} \\
\text { (end-point } \\
\text { titer) }\end{array}$ \\
\hline DB2 & Crested goshawk (Accipiter trivirgatus) & na & Bukit Panjang & March 2011 & $10^{3}$ \\
\hline DB3 & White-bellied sea eagle (Haliaeetus leucogaster) & na & Changi Airport & March 2011 & $10^{2}$ \\
\hline DB4 & Changeable hawk-eagle (Nisaetus cirrhatus) & na & Jurong West HDB & April 2011 & $10^{2}$ \\
\hline DB9 & Crested serpent eagle (Spilornis cheela) & na & Not available & May 2011 & $10^{3}$ \\
\hline DB13 & Oriental honey-buzzard (Pernis ptilorhyncus) & na & Japanese Garden & May 2011 & $10^{2}$ \\
\hline DB14 & Black-crowned night heron (Nycticorax nycticorax) & na & Pasir Ris Park & May 2011 & $10^{1}$ \\
\hline DB20 & White-bellied sea eagle (Haliaeetus leucogaster) & na & Lim Chu Kang MRT & Not available & $10^{2}$ \\
\hline DB31 & White-bellied sea eagle (Haliaeetus leucogaster) & na & Upper Seletar Reserve & April 2011 & $10^{1}$ \\
\hline DB38 & White-bellied sea eagle (Haliaeetus leucogaster) & na & Tuas & March 2012 & $10^{1}$ \\
\hline DB41 & Cattle egret (Bubulcus ibis) & na & Jurong East & July 2012 & $10^{3}$ \\
\hline DB59 & Little egret (Egretta garzetta) & na & Japanese Garden & October 2012 & $10^{1}$ \\
\hline DB71 & Heron (not identified to species) & na & Avian Sanctuary & Not available & $10^{2}$ \\
\hline MP10 & Wild boar (Sus scrofa) & na & Central Catchment Nature Reserve & Mar 2013 & $10^{2}$ \\
\hline MP12 & Wild boar (Sus scrofa) & na & Central Catchment Nature Reserve & April 2013 & $10^{1}$ \\
\hline MP19 & Wild boar (Sus scrofa) & na & Central Catchment Nature Reserve & June 2013 & $10^{2}$ \\
\hline MP27 & Wild boar (Sus scrofa) & na & Central Catchment Nature Reserve & July 2013 & $10^{1}$ \\
\hline MP32 & Wild boar (Sus scrofa) & Male; juvenile & Central Catchment Nature Reserve & September 2013 & $10^{1}$ \\
\hline MP33 & Wild boar (Sus scrofa) & Male; adult & Central Catchment Nature Reserve & December 2013 & $10^{1}$ \\
\hline MP38 & Wild boar (Sus scrofa) & Male; juvenile & Central Catchment Nature Reserve & December 2013 & $10^{2}$ \\
\hline MP41 & Wild boar (Sus scrofa) & Male; juvenile & Central Catchment Nature Reserve & December 2013 & $10^{2}$ \\
\hline MP44 & Wild boar (Sus scrofa) & Female; adult & Central Catchment Nature Reserve & January 2014 & $10^{2}$ \\
\hline MP45 & Wild boar (Sus scrofa) & Female; piglet & Central Catchment Nature Reserve & January 2014 & $10^{3}$ \\
\hline SC281013Gr & Chicken (Gallus domesticus) & Female; adult & Nature Reserve & October 2013 & $10^{1}$ \\
\hline SC281013Pu & Chicken (Gallus domesticus) & Female; adult & Nature Reserve & October 2013 & $10^{1}$ \\
\hline SC281013Ye & Chicken (Gallus domesticus) & Female; adult & Nature Reserve & October 2013 & $10^{2}$ \\
\hline SC031114B| & Chicken (Gallus domesticus) & Female; adult & Nature Reserve & November 2014 & $10^{1}$ \\
\hline SC031114Re & Chicken (Gallus domesticus) & Female; adult & Nature Reserve & November 2014 & $10^{1}$ \\
\hline SC031114Pu & Chicken (Gallus domesticus) & Female; adult & Nature Reserve & November 2014 & $10^{2}$ \\
\hline
\end{tabular}

Abbreviation: na, not available

Table 2 JEV seropositivity rates of migratory birds from 2010 to 2017. A total of 254 samples were screened and 24 (9.45\%) registered neutralizing antibodies towards Japanese encephalitis virus, with PRNT 80 end point titer of $10^{1}$ to $10^{3}$

\begin{tabular}{|c|c|c|c|c|c|c|c|c|}
\hline \multirow[t]{2}{*}{ Bird species } & \multicolumn{8}{|c|}{ Seropositivity rate (\%) } \\
\hline & 2010 & 2011 & 2012 & 2013 & 2014 & 2015 & 2016 & 2017 \\
\hline Plovers & $11.1(1 / 9)$ & $9.1(3 / 33)$ & $18.2(2 / 11)$ & $0(0 / 2)$ & $0(0 / 4)$ & $0(0 / 0)$ & $0(0 / 6)$ & $0(0 / 4)$ \\
\hline Common redshank & $50.0(5 / 10)$ & $69.2(9 / 13)$ & $15.4(4 / 26)$ & $0(0 / 9)$ & $0(0 / 38)$ & $0(0 / 61)$ & $0(0 / 10)$ & $0(0 / 18)$ \\
\hline
\end{tabular}

\footnotetext{
a Seropositive sera/total sera tested
} 


\section{Discussion}

With the abolishment of pig farms in 1992, the transmission of JEV in Singapore has seemingly ceased. However, various studies on the animal seroprofiles both on mainland Singapore and offshore islands from 2001 have revealed that JEV may still be actively transmitting among native animals. In this study, we provide an updated seropositivity profile of JEV among animals in Singapore. Besides considering the wild birds as effective sentinels, sentinel chickens were also deployed at NR to determine if there was any transmission amongst wild birds.

Although no JEV RNA was detected in any of the avian samples, JEV neutralizing antibodies were detected in ardeid birds and raptors. Egrets and herons are known avian reservoirs for JEV, but not raptors. Raptors, however, are susceptible to West Nile Virus infection (WNV), a flavivirus in the JEV antigenic complex [29]. It is interesting to note that raptors, such as the honey buzzard and white-bellied sea eagle, are non-terrestrial birds and roost in tall trees. Therefore, they are usually not available for feeding by Culex tritaeniorhynchus, the main vector of JEV, which is a terrestrial biter. This suggests the presence of a canopy biter, which is involved in the horizontal transmission of JEV to raptors [28]. Alternatively, transmission via consumption of infected prey could be a possible route, in the same manner as the transmission of WNV among birds of prey such as owls, falcons, ospreys, vultures, and bald and golden eagles.

Out of the 24 migratory birds that had neutralizing antibodies towards JEV, six were Mongolian plovers (Charadrius mongolus) and the rest were common red shanks (Tringa totanus). Interestingly, JEV seropositive birds were only detected between 2010 and 2012, during which notable JEV outbreaks in this region occurred in East Asia, namely China and Korea [30, 31]. From 2013 to 2017, none of the birds sampled were seropositive. In the same period, JEV outbreaks were largely reported in Southeast Asian countries such as Philippines and Myanmar $[32,33]$. The pattern of seropositivity detected here could be related to the movement of the birds. These migratory birds of the EAAF are known to breed in the northern regions, e.g. Mongolia, Russia, Tibet, and Alaska, and over-winter in East and Southeast Asia, Australia and New Zealand [34, 35]. However, the specific stopover points are not well known. Further studies to map out the flight path of these birds are needed.

The seroconversion of sentinel chickens placed in NR in October 2013 and November 2014 suggested active JEV transmission within the reserve during this time period. In this setting where ardeid birds and suitable mosquito vectors coexist, and migratory birds visit annually, the ecology is supportive of JEV transmission. However, the source
Table 3 Culex species and total number of mosquitoes trapped at Nature Reserve

\begin{tabular}{ll}
\hline Mosquito species & No. trapped \\
\hline Culex (Culex) bitaeniorhynchus & 166 \\
Culex (Culex) gelidus & 25 \\
Culex (Culex) quinquefasciatus & 307 \\
Culex (Culex) sitiens & 1559 \\
Culex (Culex) tritaeniorhynchus & 176 \\
Culex spp. (vishnui subgroup) & 26,146 \\
Total Culex spp. & 28,379 \\
\hline
\end{tabular}

of JEV infection remains undetermined. Over 28,000 Culex mosquitoes were screened, and no infected mosquitoes were found at NR throughout the duration of our study (Table 3). There were no human cases of JEV infection in Singapore reported during the same period. This is perhaps because the mosquito vectors are nocturnal and NR is closed at night; there is therefore little opportunity for an infected mosquito to encounter a human host. Moreover, NR is a heritage park with a rich biodiversity, including a sizable avian population which provide blood meals to these mosquitoes. No JEV cases have been detected through EHI's febrile disease surveillance programme which has screened over 10,000 dengue negative samples since 2014 (unpublished data). The absence of human cases may also be due to high asymptomatic rate, and low suspicion index for JEV infections by healthcare practitioners in a country where JEV is not known to be endemic. Nevertheless, environmental management to keep mosquito population low remains the key in minimizing transmission of mosquito-borne diseases.

Neutralizing antibodies were detected in 10 out of 66 wild boars. We observed that JEV-specific antibodies were also detected in juveniles and hence, postulated that these were maternal antibodies. Presence of antibodies in adults suggests that transmission of JEV is active in this location. No JEV RNA was detected in the wild boars, indicating absence of viremia at the point of blood collection. This phenomenon was also observed in countries that are known to be endemic for JEV, such as Japan [16, 17]. Direct pig-to-pig transmission of JEV may also facilitate the virus circulation within the wild boar population [36].

\section{Conclusions}

Our results suggest active transmission of JEV in two areas (Central Catchment Nature Reserve and NR) in Singapore involving avian and porcine hosts, nearly thirty years after the abolishment of pig farming. Further risk assessment studies will focus on identifying spatial risk of JEV in Singapore through surveillance of vector and animal hosts. 


\section{Abbreviations}

NR: nature reserve; AS: avian sanctuary; CCNR: Central Catchment Nature Reserve; EAAF: East-Asia Australasian flyway.

\section{Acknowledgements}

The authors wish to thank National Parks Board and Wildlife Reserves Singapore for their support and assistance in sample provision and sharing of professional knowledge. We would also like to thank colleagues at EHI for technical assistance and discussions, particularly Lian Jing Er, Quek Hui Leng, Dr. Chong Chee Seng, Dr. Christina Liew and Dr. Chanditha Hapuarachchi.

\section{Authors' contributions}

GY, LXF, MH, GLY, DM, MK and LYL were involved in laboratory analysis of samples. GY, SC and NLC were involved in the study design. GY, LXF, MH, GLY, DM, MK and NLC were involved in the drafting and appraisal of the manuscript. GY was involved in the interpretation of findings. $L X F, H C B, M H, G L Y, D M, M K$ and $\mathrm{CO}$ were involved in the collection of samples. All authors read and approved the final manuscript.

\section{Funding}

This study was funded by both the Ministry of Environment and Water Resources and the Ministry of Finance, Singapore.

\section{Availability of data and materials}

Data supporting the conclusions of this article are provided within the article. The datasets used and/or analysed during the present study are available from the corresponding author upon reasonable request.

\section{Ethics approval and consent to participate}

Sentinel chicken rearing, phlebotomy and euthanasia was approved by the institutional animal ethics committee under IUCUC no. 5.

\section{Consent for publication}

Not applicable.

\section{Competing interests}

The authors declare that they have no competing interests.

\section{Author details}

${ }^{1}$ Environmental Health Institute, National Environment Agency, Singapore, Singapore. ${ }^{2}$ Department of Biological Sciences, National University of Singapore, Singapore, Singapore. ${ }^{3}$ National Parks Board, Singapore, Singapore. ${ }^{4}$ Wildlife Reserves Singapore, Singapore, Singapore.

Received: 23 November 2018 Accepted: 9 May 2019

Published online: 17 May 2019

\section{References}

1. Erlanger TE, Weiss S, Keiser J, Utzinger J, Wiedenmayer K. Past, present, and future of Japanese encephalitis. Emerg Infect Dis. 2009;15:1-7.

2. Solomon T, Dung NM, Kneen R, Gainsborough M, Vaughn DW, Khanh VT. Japanese encephalitis. J Neurol Neurosurg Psychiatry. 2000;68:405-15.

3. Solomon T, Ni H, Beasley DW, Ekkelenkamp M, Cardosa MJ, Barrett AD. Origin and evolution of Japanese encephalitis virus in southeast Asia. J Virol. 2003;77:3091-8.

4. Schuh AJ, Ward MJ, Leigh Brown AJ, Barrett AD. Dynamics of the emergence and establishment of a newly dominant genotype of Japanese encephalitis virus throughout Asia. J Virol. 2014;88:4522-32.

5. Pan XL, Liu H, Wang HY, Fu SH, Liu HZ, Zhang HL, et al. Emergence of genotype I of Japanese encephalitis virus as the dominant genotype in Asia. J Virol. 2011;85:9847-53.

6. Paul FM. Morbidity and mortality of Japanese B encephalitis in Singapore. J Singapore Paediatr Soc. 1987;29(Suppl. 1):87-93.

7. Paul FM. Japanese B. encephalitis in Singapore children. J Singapore Paediatr Soc. 1978;20:13-7.

8. Chan YC, Loh TF. Isolation of Japanese encephalitis virus from the blood of a child in Singapore. Am J Trop Med Hyg. 1966;15:567-72.
9. Phoon WO. Japanese encephalitis in Singapore children. Singapore Med J. 1963;3:11-7.

10. Hale JH, Lim KA, Colless DH. Investigation of domestic pigs as a potential reservoir of Japanese B encephalitis virus on Singapore Island. Ann Trop Med Parasitol. 1957;51:374-9.

11. Hale JH, Colless DH, Lim KA. Investigation of the Malaysian form of Culex tritaeniorhynchus as a potential vector of Japanese B encephalitis virus on Singapore Island. Ann Trop Med Parasitol. 1957;51:17-25.

12. Sabchareon A, Yoksan S. Japanese encephalitis. Ann Trop Paediatr. 1998;18(Suppl.):S67-71.

13. Koh YL, Tan BH, Loh JJ, Ooi EE, Su SY, Hsu LY. Japanese encephalitis, Singapore. Emerg Infect Dis. 2006;12:525-6.

14. See E, Tan HC, Wang D, Ooi EE, Lee MA. Presence of hemagglutination inhibition and neutralization antibodies to Japanese encephalitis virus in wild pigs on an offshore island in Singapore. Acta Trop. 2002;81:233-6.

15. Ting SH, Tan HC, Wong WK, Ng ML, Chan SH, Ooi EE. Seroepidemiology of neutralizing antibodies to Japanese encephalitis virus in Singapore: continued transmission despite abolishment of pig farming? Acta Trop. 2004;92:187-91.

16. Nidaira M, Kyan H, Taira K, Okano S, Oshiro T, Kato T, et al. Survey of Japanese encephalitis virus in pigs and wild boars on Ishigaki and Iriomote Islands in Okinawa, Japan. Epidemiol Infect. 2014;142:856-60.

17. Hamano M, Lim CK, Takagi H, Sawabe K, Kuwayama M, Kishi N, et al. Detection of antibodies to Japanese encephalitis virus in the wild boars in Hiroshima prefecture, Japan. Epidemiol Infect. 2007;135:974-7.

18. Yong $\mathrm{DL}$, Lee BPY-H, Ang A, Tan KH. The status on Singapore island of the Eurasian wild pig Sus scrofa. Nat Singapore. 2010;3:227-37.

19. van den Hurk AF, Ritchie SA, Mackenzie JS. Ecology and geographical expansion of Japanese encephalitis virus. Annu Rev Entomol. 2009:54:17-35.

20. Solomon T. Control of Japanese encephalitis-within our grasp? N Engl J Med. 2006;355:869.

21. Nga PT, del Carmen Parquet M, Cuong VD, Ma SP, Hasebe F, Inoue S, et al. Shift in Japanese encephalitis virus (JEV) genotype circulating in northern Vietnam: implications for frequent introductions of JEV from Southeast Asia to East Asia. J Gen Virol. 2004:85:1625-31.

22. Scherret JH, Poidinger M, Mackenzie JS, Broom AK, Deubel V, Lipkin WI, et al. The relationships between West Nile and Kunjin viruses. Emerg Infect Dis. 2001;7:697-705.

23. Santhosh SR, Parida MM, Dash PK, Pateriya A, Pattnaik B, Pradhan HK, et al. Development and evaluation of SYBR Green I-based one-step real-time RT-PCR assay for detection and quantitation of Japanese encephalitis virus. J Virol Methods. 2007:143:73-80.

24. Chaskopoulou A, Dovas Cl, Chaintoutis SC, Kashefi J, Koehler P, Papanastassopoulou M. Detection and early warning of West Nile Virus circulation in Central Macedonia, Greece, using sentinel chickens and mosquitoes. Vector Borne Zoonotic Dis. 2013;13:723-32.

25. Kwan JL, Kluh S, Madon MB, Nguyen DV, Barker CM, Reisen WK. Sentinel chicken seroconversions track tangential transmission of West Nile virus to humans in the greater Los Angeles area of California. Am J Trop Med Hyg. 2010;83:1137-45.

26. Nemeth NM, Oesterle PT, Bowen RA. Passive immunity to West Nile virus provides limited protection in a common passerine species. Am J Trop Med Hyg. 2008;79:283-90.

27. Nemeth NM, Bosco-Lauth AM, Bowen RA. Cross-protection between West Nile and Japanese encephalitis viruses in red-winged blackbirds (Agelaius phoeniceus). Avian Dis. 2009;53:421-5.

28. Nemeth N, Bosco-Lauth A, Oesterle P, Kohler D, Bowen R. North American birds as potential amplifying hosts of Japanese encephalitis virus. Am J Trop Med Hyg. 2012;87:760-7.

29. Busquets N, Bertran K, Costa TP, Rivas R, de la Fuente JG, Villalba R, et al. Experimental West Nile virus infection in Gyr-Saker hybrid falcons. Vector Borne Zoonotic Dis. 2012;12:482-9.

30. Tao Z, Liu G, Wang M, Wang H, Lin X, Song L, et al. Molecular epidemiology of Japanese encephalitis virus in mosquitoes during an outbreak in China, 2013. Sci Rep. 2014;4:4908.

31. Seo HJ, Kim HC, Klein TA, Ramey AM, Lee JH, Kyung SG, et al. Molecular detection and genotyping of Japanese encephalitis virus in mosquitoes during a 2010 outbreak in the Republic of Korea. PLoS ONE. 2013;8:e55165 
32. Myanmar Ministry of Health. Annual report of Vector Borne Diseases Control Program. Nay PT: Myanmar Ministry of Health; 2013.

33. Lopez AL, Aldaba JG, Roque VG Jr, Tandoc AO 3rd, Sy AK, Espino FE, et al. Epidemiology of Japanese encephalitis in the Philippines: a systematic review. PLoS Negl Trop Dis. 2015;9:e0003630.

34. Li JGMTD. Migratory birds of Sungei Buloh wetland reserve. 2nd ed. Singapore: National Parks Board; 2012

35. Yong DL, Jain A, Liu Y, lqbal M, Choi CY, Crockford NJ, et al. Challenges and opportunities for transboundary conservation of migratory birds in the East Asian-Australasian flyway. Conserv Biol. 2018;32:740-3.
36. Diallo A, Chevalier V, Cappelle J, Duong V, Fontenille D, Duboz R. How much does direct transmission between pigs contribute to Japanese encephalitis virus circulation? A modelling approach in Cambodia. PLoS ONE. 2018;13:18.

\section{Publisher's Note}

Springer Nature remains neutral with regard to jurisdictional claims in published maps and institutional affiliations.
Ready to submit your research? Choose BMC and benefit from:

- fast, convenient online submission

- thorough peer review by experienced researchers in your field

- rapid publication on acceptance

- support for research data, including large and complex data types

- gold Open Access which fosters wider collaboration and increased citations

- maximum visibility for your research: over $100 \mathrm{M}$ website views per year

At BMC, research is always in progress.

Learn more biomedcentral.com/submissions 